\title{
Six-year follow-up in patients with urinary stress incontinence treated with Altis $®$ single-incision sling: a prospective single-center study
}

\begin{abstract}
Objetives: Single incision slings are the latest generation of suburethral bands that seek to minimize morbidity and major complications of transobturator bands. In short and medium term, their results in terms of success and safety are similar to transobturator and retropubic bands. Nevertheless, there is little data on their long-term outcomes. Our objective was to evaluate safety and efficacy of Altis ${ }^{\circledR}$ mini-sling during the short, medium and long-term follow-up.
\end{abstract}

Methods: Prospective observational study in 67 women who underwent surgery with Altis ${ }^{\circledR}$ for a period of 6 years (2013-2019). The main variables evaluated were: total continence, objective cure and subjective cure (satisfaction). The secondary variables studied were: complications and number of pads used per day after surgery. Statistics: Student t-test or U-Mann-Whitney for quantitative variables, Chi-Square for categorical variables.

Results: Objective cure rates were: $96.77 \%, 87.04 \%, 87.50 \%, 85.71 \%, 76.92 \%$ and $50 \%$ (from 1 to 6years), and total continence: $85.48 \%, 72.22 \%, 64.88 \%, 50 \%, 46.15 \%$ and $50 \%$ (from 1 to 6years). Degree of satisfaction was: $9,8.2,8.3,7.7,7.6$ and 6.5 points (from 1 to 6years).

30 patients (44.78\%) had some type of complication and the most common were: "de novo" urinary urgency $(20.90 \%)$, recurrence of stress urinary incontinence $(14.93 \%)$ and pain $(5.97 \%)$

Conclusion: Altis ${ }^{\circledR}$ presents high rates of objective and subjective continence in short and medium-term (1-5years), during 6-year follow-up. It is safe and does not associate severe complications. We found a high percentage of "de novo" urgency and recurrence of stress urinary incontinence, especially after the fifth year.
Volume 12 Issue 2 - 202|

\author{
Dakota Viruega-Cuaresma,' Sonia De-Miguel- \\ Manso,',2 Elena García-García,' Carmen \\ E Badillo-Bercebal,' Julio A Gobernado- \\ Tejedor,' Marta Pérez-Febles' \\ 'Servicio de Obstetricia y Ginecología, Hospital Clínico \\ Universitario de Valladolid, Gerencia Regional de Salud de \\ Castilla y León (SACYL), Spain \\ ${ }^{2}$ Departamento de Pediatría e Inmunología, Obstetricia y \\ Ginecología, Nutrición y Bromatología, Psiquiatría e Historia de \\ la Ciencia, Facultad de Medicina, Universidad de Valladolid, Spain
}

Correspondence: Dakota Viruega-Cuaresma, Dakota ViruegaCuaresma, Servicio de Obstetricia y Ginecología, Hospital Clínico Universitario de Valladolid, Gerencia Regional de Salud de Castilla y León (SACYL), España, Avenida Ramón y Cajal 3, 47005 Valladolid, España, Spain, Tel +34667219280,

Email dviruegacuaresma@gmail.com

Received: February 22, 2021 | Published: March 15, 202 I

Keywords: altis ${ }^{\circledR}$, six-year follow-up, urinary stress incontinence

Key message: There is little data on their medium and longterm outcomes. Altis ${ }^{\circledR}$ presents high rates of objective and subjective continence in short and medium-term, during 6-year follow-up.

Abbreviations: SUI, stress urinary incontinence; SIS, single incision sling; MUI, mix urinary incontinence; POP, pelvic organ prolapse; BMI, age and body mass index; UDS, urodynamic study

\section{Introduction}

Stress urinary incontinence (SUI) is defined according to the ICS (International Continence Society) terminology standardization, such as involuntary loss of urine after physical exertion (sport, activity) or after coughing or sneezing. ${ }^{1}$ It is estimated that its pre-valence in the postmenopausal female population ranges between 10 and $40 \%$, representing the most common form of incontinence. ${ }^{2,3}$ These symptoms affect physically and psychologically in patient's quality of life.

Treatment of SUI depends on the degree of severity. ${ }^{4}$ In general, therapy is initiated by indicating lifestyle modifications and rehabilitation of the pelvic floor musculature. ${ }^{4,5}$ However, in moderate and severe cases, surgery is positioned as the treatment of choice for the majority of patients. ${ }^{6}$

Introduction of synthetic suburethral polypropylene bands represents one of the most significant surgical advances in recent decades, replacing retropubic colposuspension (the traditional SUI's surgical approach), ${ }^{7}$ positioning itself as the "gold standard" for the surgical treatment of SUI. ${ }^{8}$

The minimally invasive single incision sling (SIS) or mini-slings are the latest generation of suburethral bands, and they were born in 2006. Mini-slings were designed with the aim of minimizing the morbidity and major complications of transobturator bands. ${ }^{9}$

The published studies evaluating SIS's efficacy in the short and medium term are encouraging, reflecting success and safety rates similar to transobturator and retropubic bands..$^{10-13}$ Nevertheless, it is not yet possible to take a firm stance on this new generation of suburethral bands.

Altis ${ }^{\circledR}$ single-incision sling (Coloplast Corp., Minneapolis, $\mathrm{MN}$, USA) has the property of providing an adjustable tension to the implant. It was approved by the United Stated Food and Drug Administration (FDA) in 2012 and is indicated for the treatment of female SUI secondary to urethral hypermobility and/or intrinsic sphincter deficiency.

The limited data published is mostly short-term follow-up. The objective of our study was to evaluate the safety and efficacy of the Altis ${ }^{\circledR}$ mini-sling for SUI during the short, medium and long-term follow-up. 


\section{Materials and methods}

A prospective observational study was conducted in 67 women with SUI who underwent surgery with an Altis ${ }^{\circledR}$ mini-sling for a period of 6years (2013-2019).

All the patients were operated on at the Universitary Clinic Hospital of Valladolid and evaluated at the Pelvic Floor Unit. The surgeries were performed by two gynecologists as an outpatient procedure, following the same surgical technique, under sedation and local anesthetic infiltration. They were discharged the same day, without bladder catheterization and after verifying a postvoid residue of less than $100 \mathrm{ml}$. All patients signed the informed consent before the procedure.

The inclusion criteria were that the patient presented SUI, associated or not with mixed urinary incontinence (MUI), with a predominance of stress urinary incontinence symptoms, a positive cough stress test with urethral hypermobility, and failed or unwanted previous conservative treatment for SUI.

Exclusion criteria were incontinence of neurogenic cause or suspected intrinsic urethral sphincter deficiency, the need for concomitant surgery associated with pelvic organ prolapse (POP), voiding dysfunction, and previous surgical treatment of SUI. Age and body mass index (BMI) did not limit inclusion in this study.

The patients were evaluated with respect to other variables such as anthropometrics (age and BMI), obstetric history (parity, vaginal delivery with fetus $>4 \mathrm{~kg}$, instrumented delivery with forceps), comorbidity (arterial hypertension, respiratory, neurological or psychiatric pathology), previous gynecological surgery, type of urinary incontinence (SUI, MUI), severity of SUI (grade I, II, III responding to minimal, moderate or great efforts, respectively), number of pads used, before and after surgery, and complications.

The preoperative study included: detailed medical history, exclusion of a urinary tract infection, physical examination and evaluation of incontinence (cough test, Bonney test), as well as a gynecological ultrasound to objectify the existence of urethral hypermobility and rule out pathological postvoid residual.

If the patient had MUI, the urgency component was first treated with behavioral and pharmacological interventions for at least 6 months.

Urodynamic studies (UDS) were only performed when we suspect intrinsic urethral sphincter deficiency as a potential cause of SUI and in complex urinary incontinence.

During the first 2years, the follow-up was carried out in the Pelvic Floor Unit consultation by physical examination, cough test, measurement of residual urine and visual satisfaction scale. Afterwards, annual follow-up was stablished, by telephone interview, carrying out an exhaustive anamnesis on symptoms related to SUI, urgency and urge urinary incontinence.

Patient satisfaction was established by themselves, on a scale between 0 and 10 .

The main variables evaluated were:

a. Total urinary continence: no urine leakage, neither with effort nor urgency.

b. Objective cure rates: assessed by cough test with a full bladder (250-300ml verified by ultrasound) during the first 2years, and subsequently, carrying out an exhaustive anamnesis on symptoms related to SUI, urgency and urge urinary incontinence.

c. Subjective cure rate and degree of satisfaction: firstly, it was established using the visual satisfaction scale (score 0-10) and after the second year, by telephone interview, with a numerical scale from 0 to 10

d. The secondary variables studied were:

e. Complications: immediate ( $<7$ days), intermediate (7-30 days) and late ( $>1$ month)

f. Number of pads used per day after surgery.

\section{Statistical analyses}

The Kolmogorov-Smirnov test was applied for quantitative variables to determine the type of distribution. The Student t-test was used to study quantitative variables with a normal distribution, and the U-Mann-Whitney test was used otherwise. The Chi-square test with Yates correction was used to study categorical variables. In all cases, less than 0.05 was the value taken as statistically significant. SSPS v. 23 was the statistic software used.

\section{Ethical approval}

Once the study was approved by the hospital's research committee (Code: FO-P07-12, approval date: 03-18-2016 and start date of the study: 02-13-2015) (Appendice-1), after giving our patients verbal informed consent by telephone, we collected the data from the clinical history of the first two years after surgery, and we completed by telephone follow-up until the sixth year.

\section{Results}

We included 67 patients operated with Altis ${ }^{\circledR}$ mini-sling, between 2013 and 2019. The demographic, clinical and urodynamic characteristics of the population are shown in Table 1. The mean age was $55.8 \pm 12.1$ years and the BMI was $26.7 \pm 4.3 \mathrm{~kg} / \mathrm{m}^{2}$. Regarding type of incontinence, $46.27 \%$ presented MUI with a predominance of stress incontinence and $53.73 \%$ pure SUI $(92.54 \%$ Grade II and $7.46 \%$ Grade III). An urodynamic study was carried out in 18 patients (28.87\%).

Table I Demographic and Total continence rate and objective cure (cough test) of patients with Altis ${ }^{\circledR}$ during the 6-year follow-up

\begin{tabular}{ll}
\hline Variable & Valor \\
\hline Age (mean, SD) & $55.8 \pm \mid 2.1$ \\
BMI (kg/m) (mean, SD) & $26.7 \pm 4.3$ \\
Tobacco (\%) & $17.39(\mid 2 / 67)$ \\
Physical activity (\%) & $42.72(3 \mid / 67)$ \\
Vaginal parity $\geq 2(\%)$ & $95.52(55 / 67)$ \\
Instrumental delivery with forceps $\geq I(\%)$ & $8.96(6 / 49)$ \\
Fetal macrosomía $\geq I(\%)$ & $19.40(\mid 3 / 52)$ \\
Medical diseases (\%) & \\
Arterial hypertension & $29.85(20 / 67)$ \\
Respiratory Pathology & $8.96(6 / 67)$ \\
Psychiatric illness & $29.85(20 / 67)$ \\
Neurological Pathology & $2.99(2 / 67)$ \\
\hline
\end{tabular}


Table Continued...

\begin{tabular}{ll}
\hline Variable & Valor \\
\hline Urinary Incotinence Type (\%) & $53.73(36 / 67)$ \\
SUI & $46.27(3$ I/67) \\
MUI & \\
Degree of SUI (\%) & $92.54(62 / 67)$ \\
Grade II & $7.46(5 / 67)$ \\
Grade III & $3.52 \pm 1.8$ \\
$\begin{array}{l}\text { Number of pads prior to surgery } \\
\text { (mean } \pm \text { SD) }\end{array}$ & $28.87(18 / 67)$ \\
$\begin{array}{l}\text { Previous Urodynamic Study (\%) } \\
\text { Surgical time (minutes) (mean } \pm S D)\end{array}$ & $27.4 \pm 10.8$ \\
\hline
\end{tabular}

$\mathrm{BMI}$, age and body mass index; SUI, stress urinary incontinence; MUI, mix urinary incontinence

All patients underwent successful Altis ${ }^{\circledR}$ placement and the intervention time was $27.4 \pm 10.8 \mathrm{~min}$. Patients who completed six year follow-up are reflected in Table 2.
Table 2 Number of patients operated with Altis $®$ who completed the followup each year during the study period

\begin{tabular}{ll}
\hline Year of follow-up & $\begin{array}{l}\text { Number of patients operated with Altis® } \\
\text { who completed the follow-up of the total }\end{array}$ \\
\hline I year & $62(67)$ \\
2 years & $54(67)$ \\
3 years & $48(67)$ \\
4 years & $28(67)$ \\
5 years & $16(67)$ \\
6 years & $2(67)$ \\
\hline
\end{tabular}

Concerning the main variables (Figure 1), the total continence rate and objective cure at 12 months were $85.48 \%$ and $96.77 \%$, respectively.

During the medium and long-term follow-up, the objective cure rates were: $87.04 \%$ (2years), $87.50 \%$ (3years), $85.71 \%$ (4years), $76.92 \%$ (5years) and $50 \%$ (6years), and total continence: $72.22 \%$ (2years), 64.88\% (3years), 50\% (4years), 46.15\% (5years) and 50\% (6years).

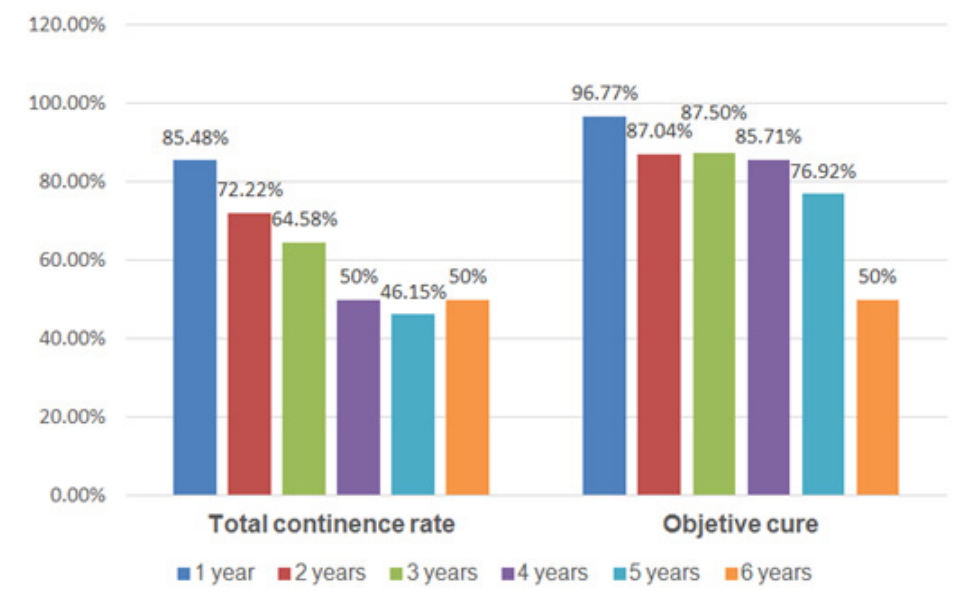

Figure I Total continence rate and objective cure (cough test) of patients with Altis $₫$ during the 6-year follow-up.

The degree of satisfaction (Figure 2) over the years was: 9 points (12 months), 8.2 (2years), 8.3 (3years), 7.7 (4years), 7.6 (5years) and
6.5 (6years). The number of pads used after surgery is reflected in Figure 2.

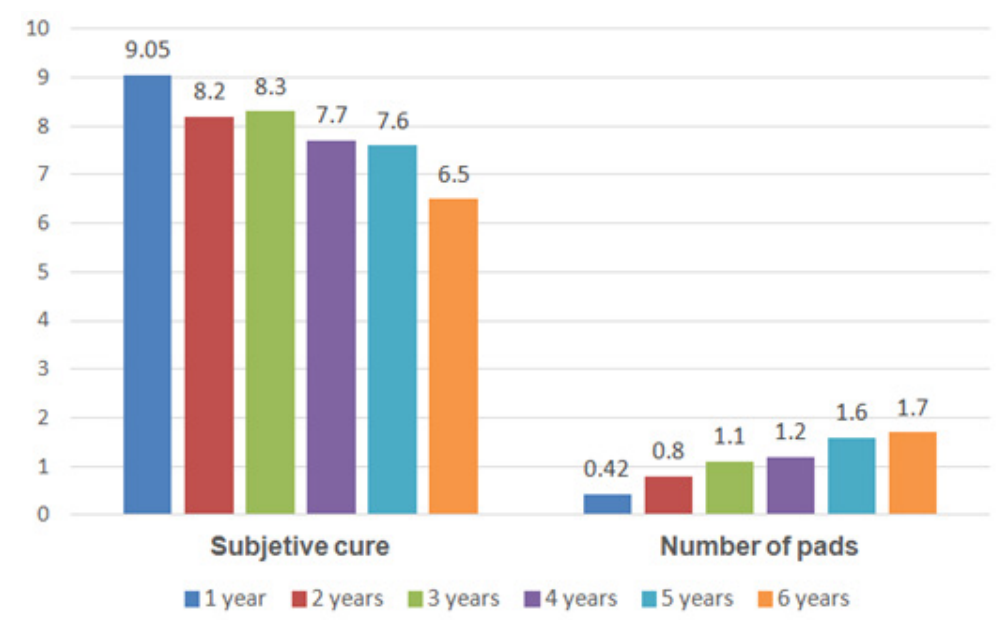

Figure 2 Satisfaction and number of pads used after Altis $®$ implantation during 6-year follow-up. 
Regarding safety, 30 patients (44.78\%) had some type of complication that we classified as immediate (first 7 days), intermediate (7-30 days) and late ( $>30$ days), which are shown in Table 3. All of them were grade I complications according to the Clavien-Dindo classification, ${ }^{14}$ except for one patient who required Altis ${ }^{\circledR}$ mesh section due to acute urine retention.

The most common complications were: "de novo" urinary urgency $(20.90 \%)$, recurrence of SUI (14.93\%) and pain (5.97\%).

Table 3 Distribution of postoperative complications with Altis $®$ during the 6-year follow-up

\begin{tabular}{lll}
\hline & Complication & $\mathbf{N}(\%)$ \\
\hline & Urinary tract infection & $2(2.99)$ \\
Immediate (8.96\%) & Urinary retention & I (I.49) \\
& Vaginal Perforation & $3(4.48)$ \\
Intermediate (2.99\%) & Urinary tract infection & $2(2.99)$ \\
& De novo urgency & $14(20.9)$ \\
Late (32.84\%) & SUl relapse & $10(14.93)$ \\
& Pain & $4(5.97)$ \\
& Vaginal mesh extrusion & $2(2.99)$ \\
\hline
\end{tabular}

SUI, stress urinary incontinence

\section{Discussion}

In the last few years, there have been several published studies evaluating the short-term efficacy and safety of the Altis ${ }^{\circledR}$ mini-sling with promising results. However, there are few studies to assess them in a long-term. It's difficult to advance the knowledge of mini-slings for several reasons, mainly due to the heterogeneity of the studies, from a methodological point of view, the type of population included and the duration of follow-up.

Most of the scientific publications are retrospective observational studies, ${ }^{13,15}$ and prospective single-center ${ }^{16,17}$ or multicenter. ${ }^{18}$ Our work is a prospective observational single-center study with a 6-year follow-up. The literature reviewed reports follow-ups at 1year, ${ }^{13,16,19,20}$ 2 years ${ }^{17,18}$ and 3years..$^{15}$

Our work includes women with a history of pure SUI and MUI with a predominance of stress incontinence, a positive cough test in consultation with urethral hypermobility, and failed or unwanted previous conservative treatment.

Exclusion criteria were incontinence of neurogenic cause, suspect intrinsic urethral sphincter deficiency, the need for concomitant surgery associated with POP, voiding dysfunction, and previous surgical treatment of SUI. These data are consistent with the criteria used by other authors. ${ }^{16,17,20}$

Overall, the objective efficacy of Altis ${ }^{\circledR}$ was high and sustained. The objective cure rate at 12 months was $96.77 \%$, which is higher from that previously reported by other authors, such as Dias ${ }^{16}$ who reports an objective cure of $90.2 \%$ and Tao $\mathrm{Jiang}^{20}$ of $91.2 \%$.

At 24 months, our objective cure decreased to $87.04 \%$, as described in other studies. Morán ${ }^{17}$ establishes a cure of $82.7 \%$ or Kocjancic ${ }^{18}$ of $87.9 \%$. These differences may be due to the criteria used to assess objective cure.

We used the cough test with a full bladder $(250-300 \mathrm{ml})$ checked by ultrasound; however, other authors such as Kocjancic ${ }^{18}$ used a $50 \%$ or more reduction in the weight of the pads. At medium-term follow-up, the objective continence rate remains stable, being $87.50 \%$ at 3 years and $85.71 \%$ at 4 years.

However, that is not the case when we speak of total continence, understanding this as the absence of urine leakage (due to urgency or effort). At 12 months, a total continence of $85.48 \%$ is reported; with a clear tendency to get worse over the years: $72.22 \%$ (2years), $64.88 \%$ (3years) and 50\% (4years). This is surely connected to the appearance of urge urinary incontinence with aging, or worsening of the urgency in MUI, rather than recurrence of SUI (most of them had a negative cough test).

At long term, the total continence rate shows a tendency to decrease: $46.15 \%$ (5years) and 50\% (6years). This long-term worsening trend is more evident in objective cure: $76.92 \%$ (5years) and 50\% (6years).

The patients presented a high degree of satisfaction, obtaining a mean of 9 points on the visual satisfaction scale in the short-term follow-up. Furthermore, no significant decrease in patient satisfaction was observed in the medium term, remaining stable between 8.2 and 7.6 points $(2-5$ years). Even at 6 years, the average score of the 2 patients who completed the 6year- follow up, was 6.5. These results are similar to those reported by Morán ${ }^{17}$ with a mean of 9.5 points at 22 months. Dias ${ }^{16}$ and Henry, ${ }^{19}$ used the ICIQ-SF questionnaire. On the other hand, the authors Kocjancic ${ }^{18}$ and D'Alessandro ${ }^{15}$ used the PGI-I questionnaire to analyze this variable, obtaining very high degree of satisfaction in $90.4 \%$ (2years) and $87.23 \%$ (3years) respectively. The quantification of subjective cure with different scores and questionnaires makes it difficult to compare the results between studies.

Our global complication rate was $44.79 \%$, higher than the $21.8 \%$ described by Morán, ${ }^{17}$ who only considers as complications: vaginal erosion, acute urine retention, voiding dysfunction and pain. Morán does not include urgency or recurrence, which may justify this disparity of percentages.

There were no severe complications. Late complications (32.84\%) were the most frequent, followed by immediate $(8.96 \%)$ and intermediate $(2.99 \%)$. There were 2 mesh extrusions $(2.99 \%)$, same proportion as for other authors: $1.92 \%(16), 2.12 \%(15), 3.50 \%(18)$ and $2.94 \%(20)$. In contrast, Morán ${ }^{17}$ does not report any extrusion in his series.

Perhaps, the most striking feature is the percentage of women with "de novo" urgency $(20.90 \%)$, higher than the figures described by $\operatorname{Moran}^{17}(8.1 \%)$, D'Alessandro ${ }^{15}$ (6.38\%) and $\operatorname{Dias}^{16}(5.9 \%)$.

A review of 10 articles including more than 2800 patients $^{21}$ that evaluated risk factors and management of overactive bladder after SUI surgery, found several risk factors for "de novo" urgency: obesity, advanced age, poor bladder capacity, high pressure detrusor or history of SUI surgery. Advanced age and previous MUI seem to be the most consistent risk factors. We did not find differences with other authors in relation to age. In our sample the mean age was 55.8years, similar to that described in other publications: 53.2 years, ${ }^{16} 56.9$ years ${ }^{15}$ and 59.7 years. ${ }^{17}$ Other factors that could influence would be: the location of the band in relation to the urethral neck, the proximity of the band to the urethral wall or the thickness of the urethra itself. We believe that careful patient selection could achieve better results.

Finally, our frequency of SUI's recurrence is not negligible, $14.93 \%$. Given the sharp drop in the objective continence rate from the fifth year, maybe a recu-rrence is more likely thereafter. 


\section{Limitations of this study}

i. The sample size is small (67) and only 2 patients completed follow-up at 6years. Therefore, long-term results cannot be evaluated.

ii. Data from the third to the sixth year were obtained by telephone interview, using a questionnaire that made it possible to rule out the presence of incontinence or urinary urgency.

\section{Conclusion}

a. The Altis ${ }^{\circledR}$ Single Incision Sling presents high objective and subjective cure rates in the short and medium-term during the 6-year follow-up.

b. It is a safe procedure that does not associate severe complications.

c. We found a high percentage of "de novo" urgency and recurrence of stress urinary incontinence during follow-up, especially after the fifth year.

\section{Acknowledgments}

None.

\section{Each author's contribution to the manuscript}

Dakota Viruega-Cuaresma, PhD: Manuscript writing, Data Collection.

Sonia De-Miguel-Manso, PhD: Project development, Manuscript writing, Data Collection.

Elena García-García, PhD: Data Collection, Manuscript writing.

Carmen E. Badillo-Bercebal, PhD: Data Collection.

Julio A. Gobernado-Tejedor, PhD, MD: Project development, Statistical analysis.

Marta Pérez-Febles, PhD: Data Collection.

\section{Funding}

No funding was obtained for the implementation of this study.

\section{Conflicts of interest}

The authors declare that they have no conflict of interest.

\section{References}

1. Haylen BT, de Ridder D, Freeman RM, et al. An International Urogynecological Association (IUGA)/International Continence Society (ICS) joint report on the terminology for female pelvic floor dysfunction. Neurourol Urodyn. 2010;29(1):4-20.

2. Hunskaar S, Lose G, Sykes D, et al. The prevalence of urinary incontinence in women in four European countries. BJU Int. 2004;93(3):324-330.

3. Melville JL, Katon W, Delaney K. Urinary incontinence in US women: a population-based study. Arch Intern Med. 2005;165:537-542.

4. Bo K, Frawley HC, Haylen BT, et al. An International Urogynecological Association (IUGA)/International Continence Society (ICS) joint report on the terminology for the conservative and nonpharmacological management of female pelvic floor dysfunction. Int Urogynecol $J$. 2017;28(2):191-213.
5. Capobianco G, Madonia M, Morelli S, et al. Management of female stress urinary incontinence: A care pathway and update. Maturitas. 2018;109:32-38.

6. Labrie J, Berghmans BL, Fischer K, et al. Surgery versus physiotherapy for stress urinary incontinence. $N$ Engl J Med. 2013;369(12):1124-1133.

7. Ford AA, Rogerson L, Cody JD, et al. Mid-urethral sling operations for stress urinary incontinence in women. Cochrane Database Syst Rev. 2017;7(7):CD006375.

8. Chapple CR, Cruz F, Deffieux X, et al. Consensus Statement of the European urology association and the European urogynaecological association on the use of implanted materials for treating pelvic organ prolapse and stress urinary incontinence. Eur Urol. 2017;72(3):424-431.

9. Meschia M, Barbacini P, Baccichet R, et al. Short-term outcomes with the Ajust system: a new single incision sling for the treatment of stress urinary incontinence. Int Urogynecol J. 2011;22(2):177- 182.

10. Abdel-Fattah M, Agur W, Abdel-All M, et al. Prospective multi-centre study of adjustable single-incision mini-sling (Ajust) in the management of stress urinary incontinence in women: 1-year follow-up study. BJU Int. 2011;109(6):880-886.

11. Cornu JN, Peyrat L, Skurnik A, et al. Ajust single incision transobturator sling procedure for stress urinary incontinence: results after 1-year followup. Int Urogynecol J. 2012;23:1265-1270.

12. Mostafa A, Lim CP, Hopper L, et al. Single-incision mini-slings versus standard midurethral slings in surgical management of female stress urinary incontinence: an updated systematic review and meta-analysis of effectiveness and complications. Eur Urol. 2014;65:402-427.

13. Erickson T, Roovers JP, Gheiler E, et al. A multicenter prospective study evaluating efficacy and safety of a single-incision sling procedure for stress urinary incontinence. J Minim Invasive Gynecol. 2021;28(1):93-99.

14. Dindo D, Demartines N, Clavien PA. Classification of surgical complications: a new proposal with evaluation in a cohort of 6,336 patients and results of a survey. Ann Surg. 2004;240:205-213.

15. D'Alessandro G, Leone M, Antolini J, et al. Three-year follow-up in patients with urinary stress incontinence treated with Altis ${ }^{\circledR}$ singleincision sling. Minerva Ginecol. 2020;72(1):12-18.

16. Dias J, Xambre L, Costa L, et al. Short-term outcomes of Altis ${ }^{\circledR}$ singleincision sling procedure for stress urinary incontinence: a prospective single-center study. Int Urogynecol J. 2014;25:1089-1095.

17. Morán E, Pérez-Ardavín J, Sánchez JV, et al. Mid-term safety and efficacy of the ALTIS ${ }^{\circledR}$ single-incision sling for female stress urinary incontinence: less mesh, same results. BJU Int. 2019;123:E51-E56.

18. Kocjancic E, Erickson T, Tu L-M, et al. Two-year outcomes for the Altis ${ }^{\circledR}$ adjustable single incision sling system for treatment of stress urinary incontinence. Neurourol Urodyn. 2017;36:1582-1587.

19. Henry de Villeneuve M, Boualaoui I, El Kharroubi A, et al. Shortterm evaluation of Altis ${ }^{\circledR}$ single-incision sling in women stress urinary incontinence. Prog Urol. 2020;30(6):346-352.

20. Jiang T, Xia Z, Cheng D, et al. Short-term outcomes of adjustable singleincision sling (Ajust $\mathrm{T}^{\mathrm{TM}}$ ) procedure for stress urinary incontinence: a prospective single-center study. Eur J Obstet Gynecol Reprod Biol. 2015;186:59-62.

21. Marcelissen T, Van Kerrebroeck P. Overactive bladder symptoms aftermidurethral sling surgery in women: risk factors and management. Neurourol Urodyn. 2018;37:83-88. 